07.2;09.1;14.1

\title{
Использование микродисковых лазеров с квантовыми точками InAs/InGaAs для биодетектирования
}

\author{
(C) М.В. Фетисова ${ }^{1}$, А.А. Корнев ${ }^{1}$, А.С. Букатин ${ }^{1}$, Н.А. Филатов ${ }^{1}$, И.Е. Елисеев ${ }^{1}$, Н.В. Крыжановская ${ }^{1,2}$, \\ И.В. Редуто ${ }^{1,2,4}$, Э.И. Моисеев ${ }^{1}$, М.В. Максимов ${ }^{1,3}$, А.Е. Жуков ${ }^{1,2}$ \\ ${ }^{1}$ Санкт-Петербургский национальный исследовательский Академический университет РАН, Санкт-Петербург, Россия \\ ${ }^{2}$ Санкт-Петербургский политехнический университет Петра Великого, Санкт-Петербург, Россия \\ ${ }^{3}$ Физико-технический институт им. А.Ф. Иофрфе РАН, Санкт-Петербург, Россия \\ ${ }^{4}$ Университет Восточной Финляндии, Йоэнсуу, Финляндия \\ E-mail: fetmarina57@gmail.com
}

Поступило в Редакцию 19 июля 2019г.

В окончательной редакции 19 июля 2019г.

Принято к публикации 19 августа 2019г.

\begin{abstract}
Показана возможность использования для биодетектирования микродисковых лазеров диаметром $\sim 10 \mu \mathrm{m}$ с активной областью на основе квантовых точек InAs/InGaAs, синтезированных на подложках GaAs. В качестве детектируемого объекта использовались химерные моноклональные антитела к белку CD20, ковалентно прикрепляемые к поверхности микродисковых лазеров, работающих при оптической накачке и комнатной температуре в водной среде. Показано, что присоединение вторичных антител приводит к увеличению пороговой мощности лазерной генерации, а также к увеличению полуширины резонансной лазерной линии.
\end{abstract}

Ключевые слова: биосенсор, полупроводниковый лазер, микродисковый лазер, квантовые точки, фотолюминесценция.

DOI: 10.21883/PJTF.2019.23.48711.17994n

Моды шепчущей галереи (МШГ) в микрорезонатоpax названы по аналогии с акустическими волнами, которые распространяются вдоль стены одноименной галереи собора Св. Павла в Лондоне. Использование оптических микрорезонаторов с МШГ позволяет реализовать сверхмалый модовый объем и чрезвычайно высокую добротность [1]. Резонаторы с МШГ перспективны для множества практических приложений, среди которых низкопороговые лазеры [2,3], интегральные фотонные устройства [4,5], оптические сенсоры [6-9]. Также резонаторы с МШГ нашли применение в приборах оптомеханики $[10,11]$ и нелинейной оптики [12-14]. Основной механизм детектирования одиночной биомолекулы МШГ-биосенсором [2] основан на изменениях резонансной длины волны и/или полуширины резонансной линии, что вызвано возмущением, которое оказывает частица на моду микрорезонатора.

В настоящее время для детектирования биомолекул в основном используются диэлектрические микросферы, являющиеся пассивными МШГ-резонаторами [15]. В непосредственной близости от микросферы располагается оптическое волокно, по которому распространяется излучение перестраиваемого лазера. Расстояние между микросферой и волокном должно быть очень малым ( $100 \mathrm{~nm})$ для обеспечения взаимодействия быстроспадающего электромагнитного поля МШГ с волокном. Распространяющееся по оптоволокну излучение перестраиваемого лазера поглощается микрорезонатором на частотах, соответствующих МШГ.
Сдвиг частот МШГ и уменьшение их добротности преобразуется в измеряемый сигнал, который свидетельствует о присутствии биомолекул на поверхности МШГ. Положение микросферы и волокна относительно друг друга должно быть точно отрегулировано с помощью устройства нанопозиционирования, что приводит к усложнению конструкции и росту ее стоимости.

Существенное упрощение конструкции биосенсора возможно за счет применения активного элемента микролазера, чувствительного к изменению параметров окружающей среды [9]. Использование в качестве активной области микролазеров квантовых точек InAs/InGaAs, синтезированных на подложках GaAs [16], обеспечивает сильную локализацию электронов и дырок и подавление латеральной диффузии носителей заряда к боковым поверхностям, тем самым предотвращается их безызлучательная рекомбинация. В таких микролазерах диаметром $6 \mu \mathrm{m}$, погруженных в водную среду, была реализована лазерная генерация при оптической накачке и комнатной температуре [17], что открывает перспективы для создания компактных высокочувствительных устройств для биодетектирования.

В настоящей работе исследована возможность биодетектирования путем анализа характеристик лазерной генерации в таких микродисковых резонаторах при осаждении на их поверхность вторичных антител. Полупроводниковая гетероструктура была выращена методом молекулярно-пучковой эпитаксии на нелегиро- 


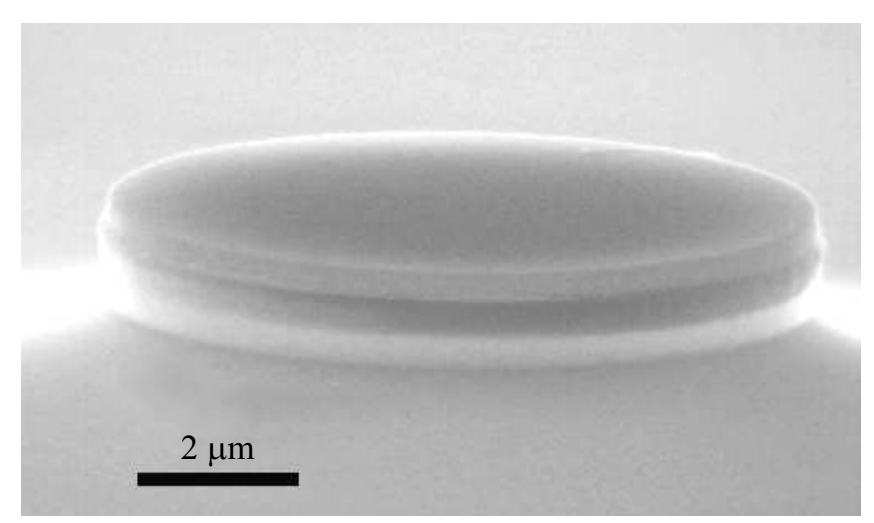

Рис. 1. Изображение исходного микролазера диаметром $10.4 \mu \mathrm{m}$, полученное с помощью сканирующего электронного микроскопа.

ванной подложке GaAs (100). После осаждения буферного слоя $\mathrm{GaAs}$ выращивался слой $\mathrm{Al}_{0.98} \mathrm{Ga}_{0.02} \mathrm{As}$ толщиной $400 \mathrm{~nm}$. Активная область помещалась в волновод $\mathrm{GaAs}$ шириной $220 \mathrm{~nm}$ и представляла собой пять слоев квантовых точек InAs/ $\mathrm{In}_{0.15} \mathrm{Ga}_{0.85} \mathrm{As}$, разделенных спейсерами GaAs толщиной $30 \mathrm{~nm}$. Спектральное положение основного перехода квантовых точек располагается вблизи $1.3 \mu \mathrm{m}$ при комнатной температуре. Микродисковые резонаторы были сформированы методом фотолитографии и ионно-лучевого травления $\left(\mathrm{Ar}^{+}\right)$. Диаметр $(D)$ резонаторов составил $10.4 \mu \mathrm{m}$. Слой $\mathrm{Al}_{0.98} \mathrm{Ga}_{0.02} \mathrm{As}$ был преобразован в оксид $(\mathrm{AlGa})_{x} \mathrm{O}_{y}$ методом селективного окисления для реализации оптического ограничения со стороны подложки, препятствующего утеканию моды в подложку (рис. 1). После этого методом атомно-слоевого осаждения микродисковые резонаторы были покрыты слоем диоксида кремния толщиной $5 \mathrm{~nm}$, который требовался для ковалентной пришивки антител к поверхности микролазера. Процесс ковалентного связывания первичных антител с поверхностью микродискового лазера осуществлялся в несколько этапов. Сначала образец покрывался поверхностно-активным веществом цетилтриметиламмония бромидом (СТАВ) [18]. Затем на поверхности пленки СТАВ активировались СООН-группы, к которым присоединялись химерные моноклональные антитела к белку CD20 путем образования ковалентной связи между карбоксильной группой на поверхности микролазера и аминогруппой на поверхности антитела с помощью реакции EDC/NHS [19].

Далее образец размещался в прозрачной ячейке, peaлизованной из полидиметилсилоксана (PDMS) и обеспечивающей смену жидкостей в ходе эксперимента. На вставке к рис. 2 представлено схематическое изображение полученной после выполнения перечисленных этапов структуры, представляющей собой покрытый слоем $\mathrm{SiO}_{2}$ микродисковый резонатор в ячейке PDMS, заполненной фосфатно-солевым буферным раствором
(PBS, показатель преломления $n_{\mathrm{PBS}} \sim 1.34$ [20]) с осажденными на поверхность микролазера первичными антителами.

Исследование спектров излучения микролазеров выполнялось при накачке лазером YLF: Nd $(527 \mathrm{~nm})$, работающим в непрерывном режиме, с использованием оптического конфокального микроскопа (Ntegra Spectra, NT-MDT) при комнатной температуре. Для фокусировки лазерного пятна диаметром $\sim 1 \mu \mathrm{m}$ на поверхности микродискового лазера в ячейке PDMS использовался объектив $\times 100$ Mitutoyo, $N A=0.5$. Этот же объектив использовался для сбора излучения микролазера, которое детектировалось с помощью моно-

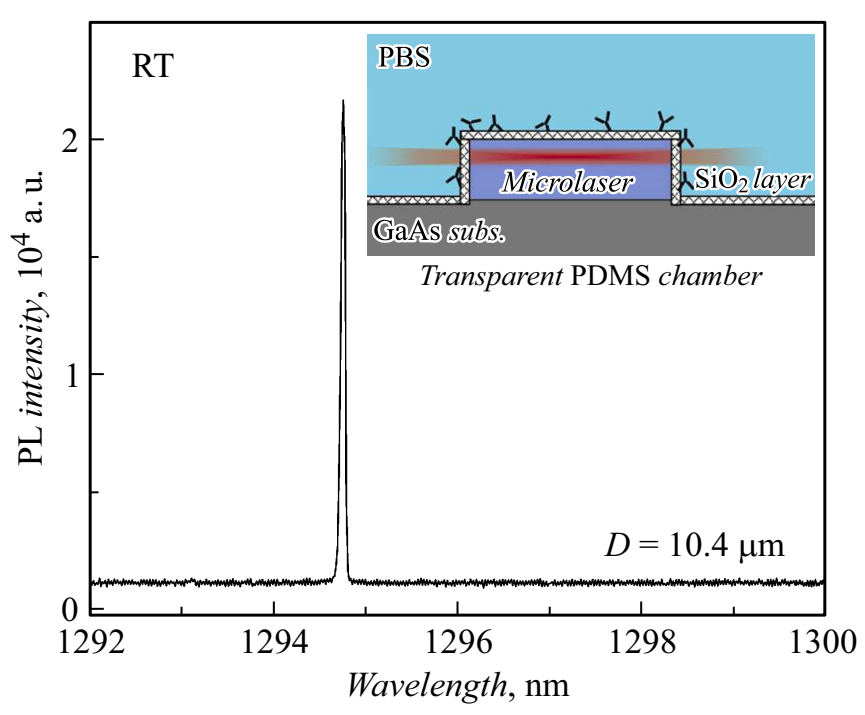

Рис. 2. Спектр лазерной генерации микродискового лазера, полученный при комнатной температуре. На вставке - схематическое изображение микродискового лазера, помещенного в среду PBS с прикрепленными первичными антителами.

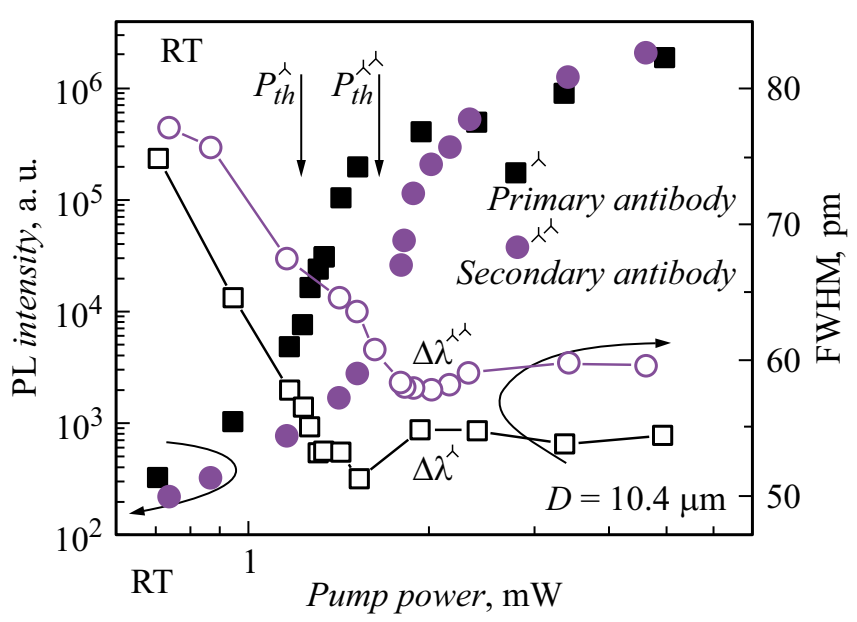

Рис. 3. Зависимость интенсивности линии и полуширины лазерной генерации от мощности оптической накачки микролазера с первичными и вторичными антителами. Пороговые мощности лазерной генерации отмечены стрелками. 
хроматора MS5204i (Sol Instruments) и многоканального охлаждаемого InGaAs-детектора iDUS (Andor). Спектральное разрешение установки составило $30 \mathrm{pm}$. Спектры излучения микролазеров исследовались при различной мощности оптической накачки с целью определения пороговых характеристик лазерной генерации: пороговой мощности оптической накачки и ширины резонансной линии вблизи порога генерации. Типичный спектр лазерной генерации микродискового лазера, покрытого первичными антителами, представлен на рис. 2. После исследования излучения микролазера с первичными антителами выполнялся процесс прикрепления вторичных антител. Для этого в ячейку PDMS с микролазерами вводился раствор вторичных моноклональных антител к легким цепям каппа (u5) и тяжелым цепям (u4) человеческих антител IgG1 в PBS в концентрации $0.1 \mu \mathrm{g} / \mathrm{ml}$. После выполнения процедуры связывания вторичных антител исследование спектров фотолюминесценции микродисковых лазеров повторялось. Для контроля связывания вторичных антител с первичными антителами, иммобилизованными на поверхности микролазеров, вторичные антитела были коньюгированы с пероксидазой хрена, визуализация которой выполнялась с помощью реакции хемилюминесценции на приборе ChemiDoc ${ }^{\mathrm{TM}}$ MP Imaging System BIO-RAD.

На рис. 3 приведены зависимости интенсивности и ширины на полувысоте лазерной линии от мощности оптической накачки для микродиска с первичными и вторичными антителами. Для обоих случаев наблюдается характерная для лазерной генерации пороговая зависимость интенсивности резонансной линии от мощности оптической накачки с одновременным уменьшением ширины линии. После покрытия исследуемого микролазера вторичными антителами наблюдается увеличение пороговой мощности с 1.36 до $1.8 \mathrm{~mW}$ и ширины резонансной линии на полувысоте с 53 до $60 \mathrm{pm}$, что, как мы полагаем, обусловлено дополнительными потерями, привносимыми вторичными антителами.

Таким образом, в работе показана возможность детектирования белков с помощью микродискового лазера с квантовыми точками InAs/InGaAs в активной области, погруженного в раствор PBS и работающего при оптической накачке. Обнаруженное существенное изменение пороговых условий генерации в микродисковом лазере (изменение пороговой накачки $>25 \%$, ширины линии генерации $>10 \%$ ) после связывания вторичных антител открывает широкие возможности применения таких лазеров для надежного детектирования различных биологических объектов. Дальнейшие исследования чувствительности пороговых характеристик микролазеров к различным условиям позволят повысить надежность и селективность биодетектирования.

\section{Финансирование работы}

Работа выполнена при поддержке Российского фонда фундаментальных исследований (РФФИ 18-02-00895) и Программы фундаментальных исследований Президиума РАH.

\section{Конфликт интересов}

Авторы заявляют, что у них нет конфликта интересов.

\section{Список литературы}

[1] Городецкий М.Л. Оптические микрорезонаторы с гигантской добротностью. М.: Физматлит, 2011. 416 с.

[2] He L., Özdemir S., Yang L. // Laser Photon. Rev. 2013. V. 7. P. 60-82. DOI: 10.1002/lpor.201100032

[3] Jiang X.F., Zou C.L., Wang L., Gong Q., Xiao Y.F. // Laser Photon. Rev. 2016. V. 10. P. 40-61. DOI: $10.1002 /$ por.201500163

[4] Yang K.Y., Dong Y.O., Lee S.H., Yang Q.F., Yi X., Shen B., Wang H., Vahala K. // Nature Photon. 2018. V. 12. P. $297-$ 302. DOI: $10.1038 / \mathrm{s} 41566-018-0132-5$

[5] Levy J.S., Gondarenko A., Foster M.A., Turner-Foster A.C., Gaeta A.L., Lipson M. // Nature Photon. 2010. V. 4. P. 37-40. DOI: $10.1038 /$ nphoton.2009.259

[6] Foreman M.R., Swaim J.D., Vollmer F. // Adv. Opt. Photon. 2015. V. 7. P. 168-240. DOI: 10.1364/AOP.7.000168

[7] Fan X., White I.M., Shopova S.I., Zhu H., Suter J.D., Sun Y. // Anal. Chim. Acta. 2008. V. 620. P. 8-26. DOI: 10.1016/j.aca.2008.05.022

[8] Yang J., Guo L.J. // IEEE J. Sel. Top. Quant. Electron. 2006. V. 12. P. 143-147. DOI: 10.1109/JSTQE.2005.862953

[9] Lu Q., Chen X., Fu L., Xie S., Wu X. // Nanomaterials. 2019. V. 9. P. 479 (1-11). DOI: 10.3390/nano9030479

[10] Kippenberg T.J., Vahala K.J. // Opt. Express. 2007. V. 15. P. 17172-17205. DOI: 10.1364/OE.15.017172

[11] Dong C., Fiore V., Kuzyk M.C., Wang H. // Science. 2012. V. 338. P. 1609-1613. DOI: $10.1126 /$ science. 1228370

[12] Armani D., Kippenberg T., Spillane S., Vahala K. // Nature. 2003. V. 421. P. 925-928. DOI: 10.1038/nature01371

[13] Jiang X., Shao L., Zhang S.X., Yi X., Wiersig J., Wang L., Gong Q., Loncar M., Yang L., Xiao Y.F. // Science. 2017. V. 358. P. 344-347. DOI: 10.1126/science.aao0763

[14] Lu Q., Liu S., Wu X., Liu L., Xu L. // Opt. Lett. 2016. V. 41. P. 1736-1739. DOI: 10.1364/OL.41.001736

[15] Ward J., Benson O. // Laser Photon. Rev. 2011. V. 5. P. $553-$ 570. DOI: $10.1002 /$ lpor.201000025

[16] Kryzhanovskaya N.V., Moiseev E.I., Polubavkina Y.S., Maximov M.V., Mokhov D.V., Morozov I.A., Kulagina M.M., Zadiranov Y.M., Lipovskii A.A., Tang M., Liao M., Wu J., Chen S., Liu H., Zhukov A.E. // Laser Phys. Lett. 2018. V. 15. P. 015802. DOI: $10.1088 / 1612-202 X / a a 9306$

[17] Fetisova M., Kryzhanovskaya N., Reduto I., Moiseev E., Blokhin S., Kotlyar K., Scherbak S., Lipovskii A., Kornev A., Bukatin A., Maximov M., Zhukov A. // J. Phys. Conf. Ser. 2018. V. 1124. P. 051007 (1-4). DOI: $10.1088 / 1742-6596 / 1124 / 5 / 051007$ 
[18] Yu Q., Hui J., Wang P., Wang X. // Inorgan. Chem. 2012. V. 51. P. 9539-9543. DOI: $10.1021 /$ ic301371q

[19] Qu W., Meng B., Yu Y., Wang S. // Mater. Sci. Eng. C. 2017. V. 76. P. 646-651. DOI: 10.1016/j.msec.2017.03.036

[20] Diéguez L., Darwish N., Mir M., Martínez E., Moreno M., Samitier J. // Sens. Lett. 2009. V. 7. P. 851-855.

DOI: $10.1166 / \mathrm{s} 1.2009 .1161$ 